\title{
Personalized absolute benefit of statin treatment for primary or secondary prevention of vascular disease in individual elderly patients
}

\author{
Manon C. Stam-Slob ${ }^{1} \cdot$ Frank L. J. Visseren ${ }^{1,8} \cdot$ J. Wouter Jukema ${ }^{2}$ • \\ Yolanda van der Graaf ${ }^{3} \cdot$ Neil R. Poulter ${ }^{4} \cdot$ Ajay Gupta $^{4} \cdot$ Naveed Sattar $^{5}$. \\ Peter W. Macfarlane ${ }^{5}$ Patricia M. Kearney ${ }^{6}$ - Anton J. M. de Craen ${ }^{7}$. \\ Stella Trompet ${ }^{2,7}$
}

Received: 21 May 2016/Accepted: 25 July 2016/Published online: 23 August 2016

(c) The Author(s) 2016. This article is published with open access at Springerlink.com

\begin{abstract}
Objective To estimate the absolute treatment effect of statin therapy on major adverse cardiovascular events (MACE; myocardial infarction, stroke and vascular death) for the individual patient aged $\geq 70$ years.

Methods Prediction models for MACE were derived in patients aged $\geq 70$ years with $(n=2550)$ and without $(n=3253)$ vascular disease from the "PROspective Study of Pravastatin in Elderly at Risk" (PROSPER) trial and validated in the "Secondary Manifestations of ARTerial disease" (SMART) cohort study $(n=1442)$ and the "Anglo-Scandinavian Cardiac Outcomes Trial-Lipid Lowering Arm" (ASCOT-LLA) trial $(n=1893)$, respectively, using competing risk analysis. Prespecified predictors were various clinical characteristics including statin treatment. Individual absolute risk reductions (ARRs) for
\end{abstract}

A. J. M. de Craen: Deceased January 2016

Electronic supplementary material The online version of this article (doi:10.1007/s00392-016-1023-8) contains supplementary material, which is available to authorized users.

Frank L. J. Visseren

f.1.j.visseren@umcutrecht.nl

1 Department of Vascular Medicine, University Medical Center Utrecht, Heidelberglaan 100, 3584 CX Utrecht, The Netherlands

2 Department of Cardiology, Leiden University Medical Center, Albinusdreef 2, 2333 ZA Leiden, The Netherlands

3 Julius Center for Health Sciences and Primary Care, University Medical Center Utrecht, Universiteitsweg 100, 3584 CG Utrecht, The Netherlands

4 Department of Vascular Medicine, ICCH, Imperial College London, White City, London W12 0NN, UK
MACE in 5 and 10 years were estimated by subtracting ontreatment from off-treatment risk.

Results Individual ARRs were higher in elderly patients with vascular disease [5-year ARRs: median 5.1\%, interquartile range (IQR) 4.0-6.2 \%, 10-year ARRs: median $7.8 \%$, IQR $6.8-8.6 \%$ ] than in patients without vascular disease (5-year ARRs: median $1.7 \%$, IQR 1.3-2.1\%, 10-year ARRs: $2.9 \%$, IQR 2.3-3.6 \%). Ninetyeight percent of patients with vascular disease had a 5-year $\mathrm{ARR} \geq 2.0 \%$, compared to $31 \%$ of patients without vascular disease.

Conclusions With a multivariable prediction model the absolute treatment effect of a statin on MACE for individual elderly patients with and without vascular disease can be quantified. Because of high ARRs, treating all patients is more beneficial than prediction-based treatment for secondary prevention of MACE. For primary prevention of MACE, the prediction model can be used to identify those patients who benefit meaningfully from statin therapy.

5 Institute of Cardiovascular and Medical Sciences, Cardiovascular Research Centre, University of Glasgow, Glasgow G12 8TA, UK

6 Department of Epidemiology and Public Health, University College Cork, Western Rd, Cork, Ireland

7 Department of Gerontology and Geriatrics, Leiden University Medical Center, Albinusdreef 2, 2333 ZA Leiden, The Netherlands

8 University Medical Center Utrecht, F02.224, P.O. Box 85500, 3508 GA Utrecht, The Netherlands 
Keywords Elderly $\cdot$ Statin $\cdot$ Absolute treatment effect . Vascular disease

\section{Introduction}

Vascular disease in the elderly (age $\geq 70$ years) accounts for a high global burden of disease as risk of atherosclerotic vascular events and their case-fatality rate increase exponentially with age [1-3]. Older patients who survive a major adverse cardiovascular event (MACE) are commonly chronically disabled because of heart failure, cardiac arrhythmia or neurologic deficits. Population aging and the chronic complications of vascular events that physicians encounter in the elderly have triggered a debate about the benefit of cardiovascular risk management in these patients. The "PROspective Study of Pravastatin in Elderly at Risk" (PROSPER) trial found a $15 \%$ reduction in myocardial infarction, stroke and coronary heart disease death with pravastatin treatment in elderly subjects [4]. Older patients are underrepresented in other trials evaluating cardiovascular prevention strategies and it is, therefore, uncertain whether statins are effective in the elderly. They have lower life-expectancy in general than middleaged individuals which could potentially limit their benefit from statins. The benefit of statins is particularly uncertain and debated in those with limited life expectancy due to nonvascular diseases [5].

Statin therapy is recommended for the secondary prevention of MACE in those who have vascular disease, unless comorbidity and polypharmacy confound management [6-8]. For the primary prevention of MACE, the European guideline states that 'statin therapy may be considered particularly in the presence of at least one other risk factor than age' and the National Institute for Health and Care Excellence (NICE) guideline advices statin therapy in those with an estimated 10-year risk of MACE $\geq 10 \%[7,9]$. Since the QRISK2 score estimates a 10 -year risk $\geq 10 \%$ for every patient aged $\geq 70$ years and almost all older patients have at least one vascular risk factor besides age, statin therapy would be indicated for nearly all elderly patients [10]. However, under-prescription of statins in daily practice may in part reflect uncertainty about the extent to which elderly patients may benefit from a statin [11]. As the absolute risk for vascular disease and the absolute risk reduction (ARR) caused by a statin are influenced by individual patient characteristics, there is a potential range in the benefit received from a statin. Therefore, we aimed to estimate the absolute treatment effect of statin therapy on MACE for the individual elderly patient by developing and validating a prediction model based on individual patient characteristics [12, 13].

\section{Materials and methods}

\section{Study populations}

We developed two separate prediction models for MACE in patients with and without vascular disease aged $\geq 70$ years, since a history of vascular disease is the strongest predictor for MACE in elderly subjects with great differences in risk profiles of elderly subjects with and without vascular disease. Moreover, guidelines differentiate between primary and secondary prevention of MACE $[6,7]$. Both models were derived in the PROSPER trial population. The model for patients with vascular disease was validated in the "Secondary Manifestations of ARTerial disease" (SMART) cohort study and the model for patients without vascular disease in the "Anglo-Scandinavian Cardiac Outcomes Trial- Lipid Lowering Arm" (ASCOT-LLA) trial. The design and patient populations of these studies have been described in detail in the original publications [4, 14, 15]. Ethical approval was obtained for these studies. The PROSPER study included patients 70-82 years of age from Scotland, Ireland and the Netherlands with vascular disease or a high risk profile for vascular disease between 1997 and 1999. Patients were randomly assigned to $40 \mathrm{mg}$ pravastatin per day or placebo. Patients from the elderly ASCOT-LLA population recruited between 1998 and 2000 were 70-79 years of age and were known to have hypertension (untreated or treated), but total cholesterol levels $\leq 6.5 \mathrm{mmol} / 1$, in combination with three additional risk factors for vascular disease. They originated from the United Kingdom, Ireland and the Nordic Countries. Study participants were randomly assigned to atorvastatin $10 \mathrm{mg}$ or placebo. All patients from the PROSPER and ASCOT-LLA trial were not taking a statin at the time of study inclusion. Elderly patients from the single-center prospective, observational SMART cohort study with a history of vascular disease from the Netherlands were 70-82 years of age and followed up between 1996 and 2014.

\section{Model derivation}

We derived prediction models in the PROSPER trial for the combined outcome of myocardial infarction, stroke and vascular death (MACE) in elderly patients with $(n=2550)$ and without $(n=3253)$ vascular disease. Vascular disease included current or prior coronary artery disease (myocardial infarction, angina, coronary artery bypass graft/ percutaneous coronary intervention), cerebrovascular disease (stroke or transient ischemic attack) or peripheral artery disease (claudication or peripheral artery surgery). We built a Fine \& Gray competing risks model to account 
for nonvascular deaths [16]. Prespecified predictors from existing risk scores in the elderly were: sex, age, current smoking, diabetes, systolic blood pressure, low density lipoprotein (LDL)-cholesterol, high-density lipoprotein (HDL)-cholesterol, glomerular filtration rate (eGFR) and number of medications taken [17-19]. Variable selection was not applied to prevent optimism, which is the phenomenon that a model optimally fits the data in which it is derived, but is not generalizable to an external population. Glomerular filtration rate was assessed with the Modification of Diet in Renal Disease (MDRD) formula [20]. Polyvascular disease (vascular disease at $\geq 1$ of the defined locations) was added as a predictor to the model for recurrent MACE. The number of medications per patient was included as a measure of comorbidity, not taking into account nasal sprays and topical skin medicines. Allocated statin treatment was added to both models. Statin treatment effect for secondary prevention of MACE was derived from the PROSPER population. For primary prevention of MACE, statin treatment effect was estimated in a pooled analysis of the PROSPER and ASCOT trial population, adjusted for potential study differences regarding statin type, patient population and clinical setting. This was done in a competing risks analysis of the pooled PROSPER and ASCOT-LLA individual patient data, with statin treatment and the trial patients originated from as independent variables. We singly imputed missing values by weighted probability matching using multivariate regression, as complete case analysis leads to loss of information and possibly to bias of coefficients [21]. Missing values were imputed for eGFR $(n=8,0.1 \%)$. Continuous predictors were truncated at the 1st and 99th percentile to minimize the influence of outliers in the model [22]. Whether the association of continuous predictors with the outcome variable was linear or not was assessed with restricted cubic splines [23].

Model performance was assessed with the c-statistic [95\% confidence interval (CI)] for discrimination and with calibration plots of predicted versus observed risk. The model was fitted for the prediction of 3.2-year risk (median follow-up). These estimations were extrapolated to derive 5-year and 10-year vascular event risks. An individual 5-year and 10-year ARR was estimated for each patient, by subtracting the predicted risk for a specific patient with statin treatment from his or her predicted risk without statin treatment $(\mathrm{ARR}=$ individual MACE risk without a statin-individual MACE risk with a statin). One can estimate the MACE risk and ARR with and without statin treatment for each individual patient by filling in patient characteristics in the model formula (Table S1). This ARR can be translated into an individual number needed to treat (iNNT), the number of patients with the exact same risk profile needed to treat to prevent 1 event in 5 or 10 years, respectively (iNNT $=100$ / ARR). For example, an estimated 5-year absolute risk reduction of $2 \%$ means that one has to treat 50 patients with the exact same risk profile for 5 years to prevent 1 event $[\mathrm{iNNT}=100 / 2(\mathrm{ARR})=50]$. The distribution of MACE risk and ARR in patients with and without vascular disease is presented in a histogram and described as median with an interquartile range (IQR).

\section{Model validation}

The derived model for patients with vascular disease was externally validated in the SMART cohort study $(n=1442)$ and the model for patients without vascular disease in the ASCOT-LLA trial $(n=1893)$. Discrimination was assessed with the c-statistic $(95 \% \mathrm{CI})$ and calibration with plots of predicted versus observed risk. To optimally estimate vascular risk and treatment effect for individual patients we adjusted for geographic differences by recalibrating the models with updated cumulative baseline hazard and mean linear predictor, while effect sizes of predictors did not change. Missing values in the ASCOT-LLA trial were imputed for creatinine $(n=54$, $2.9 \%)$, LDL-cholesterol $(n=185,9.8 \%)$ and number of medications $(n=1156,61 \%)$. In the SMART study, missing values were imputed for systolic blood pressure $(n=11,0.8 \%)$, LDL-cholesterol $(n=37,2.7 \%)$, HDLcholesterol $(n=13,0.9 \%)$, eGFR $(n=4,0.3 \%)$ and smoking $(n=10,0.7 \%)$. We estimated baseline LDL-cholesterol concentrations for patients in the SMART cohort study who were already on a statin at the time of study inclusion, according to the expected LDL-cholesterol reduction that the different statin preparations with their dosages probably had achieved [24].

\section{Sensitivity analyses}

We performed a sensitivity analysis to assess what the expected individual ARR would be if patients were treated with atorvastatin $20 \mathrm{mg}$ as recommended by the NICE guideline for primary prevention of vascular disease [9]. We assumed that atorvastatin $20 \mathrm{mg}$ gives $6 \%$ more LDLcholesterol reduction than pravastatin $40 \mathrm{mg}$ or atorvastatin $10 \mathrm{mg}$. In this scenario, the relative risk reduction with a statin would be $25 \%$ instead of $22 \%$ for secondary prevention and $15 \%$ instead of $13 \%$ for primary prevention of vascular disease. In a second sensitivity analysis, individual ARRs for primary prevention of MACE were estimated with a combined statin relative risk reduction of $16 \%$ for patients aged $\geq 75$ years from different trial populations [25]. 


\section{Net benefit analysis}

The different treatment strategies (treating none, treating all patients and treating patients according to the prediction model with a statin) were compared with each other in a net benefit analysis [26]. This method shows whether it is valid to base treatment decisions on the prediction model. Methods and results (Fig. S1, Table S2) can be found in the Supplementary material.

Analyses were performed in $\mathrm{R}$ statistical software 3.2.0 with the add-on packages rms, plyr, pec, riskRegression, and cmprsk (extended by Wolbers et al. [16]).

\section{Results}

\section{Patient population and trial outcomes}

The study population consisted of elderly patients with vascular disease (PROSPER $n=2550$, SMART $n=1442$ ) and patients without vascular disease (PROSPER $n=3253$, ASCOT-LLA $n=1893$ ). Baseline characteristics are presented in Table 1. Mean age of patients with vascular disease was 75.7 [standard deviation (SD) 3.4] years in the PROSPER trial and 73.6 (SD 2.7) years in the SMART study. Mean age of patients without vascular disease was 75.1 (SD 3.3) years in the PROSPER trial and 74.1 (SD 2.7) years in the ASCOT-LLA trial. During a median follow-up of 3.2 years in patients with vascular disease from the PROSPER trial, 517 MACE [68/1000 person years (PY)] and 114 nonvascular deaths occurred. Median follow-up in SMART patients with vascular disease was 5.4 years with 398 MACE (46/1000 PY) and 212 nonvascular deaths. Patients without vascular disease from the PROSPER trial experienced 395 MACE (39/1000 PY) and 155 nonvascular deaths. In ASCOT-LLA patients without vascular disease, median follow-up was 3.1 years with 128 MACE (22/1000 PY) and 86 nonvascular deaths.

\section{Model derivation and performance for patients with vascular disease}

The derived model in patients with vascular disease is presented in Table 2A. Baseline systolic blood pressure and LDL-cholesterol were exponentially related to the outcome. LDL-cholesterol was not a major independent predictor for MACE. There was no interaction present between statin treatment and baseline risk, baseline LDLcholesterol, LDL-cholesterol after 3 months of randomisation, age, renal function or polyvascular versus monovascular disease ( $p$ values $>0.2$ ). Model performance in the derivation set showed a good calibration (Fig. 1) and moderate discrimination [c-statistic $0.62 \quad(95 \%$ CI
0.60-0.64)]. After recalibration, the model calibrated well in the SMART validation set (Fig. 1) with a moderate discriminative performance [c-statistic $0.60 \quad(95 \%$ CI $0.56-0.63)]$.

\section{Model derivation and performance for patients without vascular disease}

The derived model for patients without vascular disease is presented in Table 2B. Renal function (eGFR) was exponentially related to the outcome. LDL-cholesterol was no independent risk factor for MACE. There was no interaction present between statin treatment and baseline risk, baseline LDL-cholesterol, LDL-cholesterol after 3 months of randomisation or age ( $p$ values $>0.4$ ). An interaction between statin treatment and eGFR $(p=0.006)$ in the derivation set was not present in the validation set and, therefore, not included in the model. The model calibrated well in the derivation set (Fig. 1) with a moderate discriminative performance [c-statistic $0.61 \quad(95 \%) \quad \mathrm{CI}$ 0.58-0.63)]. After recalibration, model calibration was good in the ASCOT-LLA validation set (Fig. 1) with a low discriminative performance [c-statistic 0.57 (95\% CI $0.53-0.63)]$.

\section{Five-year and ten-year predicted absolute risk for MACE and the absolute risk reduction if treated with a statin}

Figures 2 and 3 show the distribution of 5-year and 10-year MACE risk and the absolute risk reductions in patients with vascular disease from the PROSPER trial and SMART study, and in patients without vascular disease from the PROSPER and ASCOT-LLA trials. There was a wide distribution of MACE risk in patients with vascular disease (5year: median 26.4\%, IQR 20.3-33.6 \%, 10-year: median $46.9 \%$, IQR 38.5-57.0\%) and in those without vascular disease (5-year: median $13.7 \%$, IQR 10.4-17.8 \%, 10-year: median 25.5\%, IQR 19.8-32.4\%). Individual 5-year ARRs with a statin were higher in patients with vascular disease (median 5.1\%, IQR 4.0-6.2\%) than in patients without vascular disease (median $1.7 \%$, IQR 1.3-2.1\%). Ninetyeight percent of patients with vascular disease had a 5-year ARR $\geq 2.0 \%$ (iNNT $\leq 50)$, compared to $31 \%$ of patients without vascular disease. In patients with vascular disease the median 10-year ARR was 7.8\% (IQR 6.8-8.6\%) compared to a median 10-year ARR of $2.9 \%$ (IQR 2.3-3.6\%) in patients without vascular disease.

\section{Sensitivity analyses}

Under the assumption that atorvastatin $20 \mathrm{mg}$ lowers LDLcholesterol with an additional $6 \%$ compared to pravastatin 
Table 1 Baseline characteristics of elderly patients (age $\geq 70$ years) with and without vascular disease

\begin{tabular}{|c|c|c|c|c|}
\hline & \multicolumn{2}{|c|}{ With vascular disease } & \multicolumn{2}{|c|}{ Without vascular disease } \\
\hline & $\begin{array}{l}\text { PROSPER } \\
(n=2550)\end{array}$ & $\begin{array}{l}\text { SMART } \\
(n=1442)\end{array}$ & $\begin{array}{l}\text { PROSPER } \\
(n=3253)\end{array}$ & $\begin{array}{l}\text { ASCOT-LLA } \\
(n=1893)\end{array}$ \\
\hline \multicolumn{5}{|l|}{ Demographics } \\
\hline Male gender $(n, \%)$ & $1453(57.0)$ & $1062(73.7)$ & $1350(41.5)$ & $1525(80.6)$ \\
\hline Age (years) & $75.7(3.4)$ & $73.6(2.7)$ & $75.1(3.3)$ & $74.1(2.7)$ \\
\hline \multicolumn{5}{|l|}{ Country of residence $(n, \%)$} \\
\hline Scotland/UK ${ }^{\mathrm{a}}$ & $1232(48.3)$ & & $1288(39.6)$ & $990(52.3)$ \\
\hline Ireland & $845(33.1)$ & & $1338(41.1)$ & $19(1.0)$ \\
\hline The Netherlands & $473(18.5)$ & $1442(100)$ & $627(19.3)$ & \\
\hline Denmark & & & & $133(7.0)$ \\
\hline Finland & & & & $126(6.7)$ \\
\hline Iceland & & & & $11(0.6)$ \\
\hline Norway & & & & $205(10.8)$ \\
\hline Sweden & & & & 409 (21.6) \\
\hline Current smoker $(n, \%)$ & 474 (18.6) & $238(16.5)$ & $1084(33.3)$ & $402(21.2)$ \\
\hline$N$ medications (median, IQR) & $4(3-6)$ & $5(4-7)$ & $3(2-4)$ & $2(1-3)$ \\
\hline Statin treatment $(n, \%)$ & $1299(50.9)$ & $885(61.4)$ & $1591(48.9)$ & 939 (49.6) \\
\hline \multicolumn{5}{|l|}{ Medical history } \\
\hline Diabetes $(n, \%)$ & $224(8.7)$ & $293(20.3)$ & $399(12.3)$ & $514(27.2)$ \\
\hline \multicolumn{5}{|l|}{ Cardiovascular disease $(n, \%)$} \\
\hline Coronary artery disease & $1524(59.8)$ & $610(42.3)$ & $0(0)$ & $0(0)$ \\
\hline Cerebrovascular disease & $425(16.7)$ & $276(19.1)$ & $0(0)$ & $0(0)$ \\
\hline Peripheral artery disease & $206(8.1)$ & $238(16.5)$ & $0(0)$ & $0(0)$ \\
\hline Polyvascular disease & $395(15.5)$ & $318(22.1)$ & $0(0)$ & $0(0)$ \\
\hline \multicolumn{5}{|l|}{ Physical examination } \\
\hline Heart rate (beats/min) & $65.2(11.6)$ & $66.0(14.1)$ & $67.2(11.6)$ & $69.6(12.3)$ \\
\hline Systolic blood pressure $(\mathrm{mmHg})$ & $152(22)$ & $148(22)$ & $157(22)$ & $170(19)$ \\
\hline \multicolumn{5}{|l|}{ Laboratory measurements } \\
\hline LDL cholesterol (mmol/l) & $3.8(0.8)$ & $3.8(1.2)$ & $3.8(0.8)$ & $3.5(0.7)$ \\
\hline HDL cholesterol (mmol/l) & $1.2(0.3)$ & $1.3(0.4)$ & $1.3(0.4)$ & $1.3(0.4)$ \\
\hline eGFR $\left(\mathrm{ml} / \mathrm{min} / 1.73 \mathrm{~m}^{2}\right)$ & $58.8(14.3)$ & $66.8(16.7)$ & $61.0(14.7)$ & $63.6(11.8)$ \\
\hline
\end{tabular}

Data are displayed as mean (SD) unless indicated otherwise

a $U K$ United Kingdom

$40 \mathrm{mg}$ or atorvastatin $10 \mathrm{mg}$, the median 5-year ARR would be $6.0 \%$ (IQR 4.7-7.3\%) in patients with vascular disease and $2.0 \%$ (IQR $1.5-2.5 \%$ ) in patients without vascular disease. Forty-nine percent of patients without vascular disease would have a 5-year $A R R \geq 2.0 \%$. Median 10-year ARR would be 9.3\% (IQR 8.1-10.2\%) for patients with vascular disease and $3.5 \%$ (IQR $2.8-4.2 \%$ ) for patients without vascular disease.

Assuming statin therapy reduces MACE by $16 \%$ in patients without vascular disease, the median 5-year ARR would be $2.1 \%$ (IQR 1.6-2.6\%) and the median 10-year ARR would be $3.6 \%$ (IQR 2.9-4.4\%). Fifty-three percent of patients without vascular disease would have a 5-year ARR $\geq 2.0 \%$.

\section{Discussion}

Risk for MACE and the absolute treatment effect of a statin on MACE for individual elderly patients can be estimated with a clinical prediction model containing simple, readily available patient characteristics. There is a wide distribution of MACE risk in elderly patients with and without vascular disease. For secondary prevention of MACE, treating all patients is most beneficial since predicted absolute risk reductions are almost invariably high. With the use of a prediction model that quantifies an individual's expected absolute risk reduction by statin treatment, those who benefit meaningfully from statin therapy in absolute terms in the primary prevention setting can be identified. 
Table 2 Fitted prediction models for major adverse cardiovascular events in elderly patients

\begin{tabular}{|c|c|c|c|}
\hline Variable & Coefficient & sHR $(95 \%$ CI $)$ & $p$ value \\
\hline \multicolumn{4}{|l|}{ A. Patients with vascular disease } \\
\hline Male sex & 0.401 & $1.49(1.21-1.84)$ & $<0.001$ \\
\hline Age (years) & 0.042 & $1.04(1.02-1.07)$ & 0.002 \\
\hline Current smoking & 0.240 & $1.27(1.02-1.58)$ & 0.031 \\
\hline Diabetes & 0.543 & $1.72(1.31-2.26)$ & $<0.001$ \\
\hline Polyvascular disease & 0.344 & $1.41(1.13-1.76)$ & 0.003 \\
\hline Number of medications & 0.053 & $1.06(1.01-1.10)$ & 0.009 \\
\hline Systolic blood pressure (per $10 \mathrm{mmHg}$ ) & -0.366 & & 0.084 \\
\hline Systolic blood pressure (per $10 \mathrm{mmHg})^{2}$ & 0.001 & & 0.084 \\
\hline LDL-cholesterol (mmol/l) & 0.876 & & 0.074 \\
\hline LDL-cholesterol $(\mathrm{mmol} / \mathrm{l})^{2}$ & -0.109 & & 0.080 \\
\hline HDL-cholesterol (mmol/l) & 0.081 & $1.08(0.82-1.43)$ & 0.570 \\
\hline eGFR (per $10 \mathrm{ml} / \mathrm{min} / 1.73 \mathrm{~m}^{2}$ ) & -0.053 & $0.95(0.88-1.02)$ & 0.150 \\
\hline Statin treatment & -0.245 & $0.78(0.66-0.93)$ & 0.006 \\
\hline \multicolumn{4}{|l|}{ B. Patients without vascular disease } \\
\hline Male sex & 0.283 & $1.33(1.06-1.66)$ & 0.013 \\
\hline Age (years) & 0.037 & $1.04(1.01-1.07)$ & 0.018 \\
\hline Current smoking & 0.290 & $1.34(1.07-1.68)$ & 0.012 \\
\hline Diabetes & 0.210 & $1.23(0.93-1.64)$ & 0.150 \\
\hline Number of medications & 0.090 & $1.09(1.05-1.15)$ & $<0.001$ \\
\hline Systolic blood pressure (per $10 \mathrm{mmHg}$ ) & 0.060 & $1.06(1.01-1.11)$ & 0.014 \\
\hline LDL-cholesterol (mmol/l) & 0.007 & $1.01(0.89-1.15)$ & 0.920 \\
\hline HDL-cholesterol (mmol/l) & -0.359 & $0.70(0.51-0.96)$ & 0.028 \\
\hline eGFR (per $10 \mathrm{ml} / \mathrm{min} / 1.73 \mathrm{~m}^{2}$ ) & -0.613 & & 0.008 \\
\hline eGFR $\left(\text { per } 10 \mathrm{ml} / \mathrm{min} / 1.73 \mathrm{~m}^{2}\right)^{2}$ & 0.005 & & 0.008 \\
\hline Statin treatment & -0.140 & $0.87(0.73-1.03)$ & 0.110 \\
\hline
\end{tabular}

Models derived with Fine and Gray competing risk analysis

$S H R$ subdistribution hazard ratio, $C I$ confidence interval
Current guidelines recommend statin treatment for the secondary prevention of MACE in general, but where possible treatment decisions should ideally be made per individual taking into account expected absolute treatment effect, adverse events and patient preferences [6-8]. High absolute treatment effects found in our study underline this recommendation, and moreover enable physicians to estimate the individual absolute treatment effect for a patient. There seems to be a maximal absolute risk reduction that can be achieved by a statin in this high-risk population, as a statin may delay recurrent MACE in patients at very high risk ( $\geq 70 \%$ 10-year MACE risk) rather than prevent it from happening during a lifetime. In these individuals, the benefit from statin therapy in recurrent MACE-free life years might be limited. In general, treating elderly patients with vascular disease with a statin seems beneficial as the large expected benefits are very likely to outweigh potential harms. These include adverse events like myopathy and incident type 2 diabetes, drug-drug interactions and the inconvenience of polypharmacy which impair quality of life in elderly patients in particular [27, 28]. An example of a drug-drug interaction that increases the risk of adverse events comes from the United States of America where $83 \%$ of patients with dyslipidemia is treated with a CYP3A4-metabolized statin of whom 25-30\% concomitantly use a CYP3A4-inhibitor [29]. Even though there might be a higher risk of serious adverse events in the elderly, there is no conclusive evidence for a higher incidence of rhabdomyolysis, cognitive deterioration, liver or kidney injury [30].

For primary prevention of vascular disease, current guidelines advise to treat those at high risk which means that practically everyone aged $\geq 70$ years would be given a statin since age dominates risk scores $[6,7,9]$. However, in clinical practice statin treatment rates for elderly patients are low presumably reflecting ambiguities about the absolute benefit of statin treatment for the primary prevention of vascular disease in the elderly [11]. Moreover, the incidence of severe comorbidities increases with age and emphasis might be placed on treating these inter-current 
PROSPER - patients with vascular disease

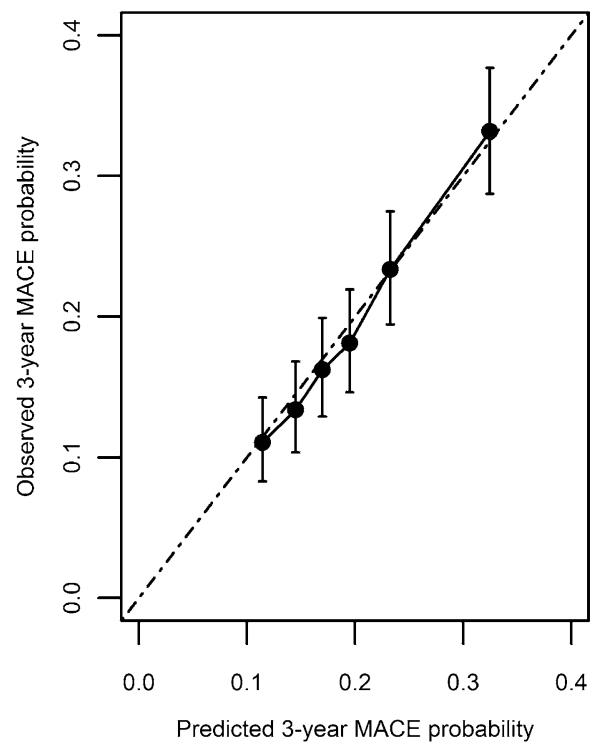

PROSPER - patients without vascular disease

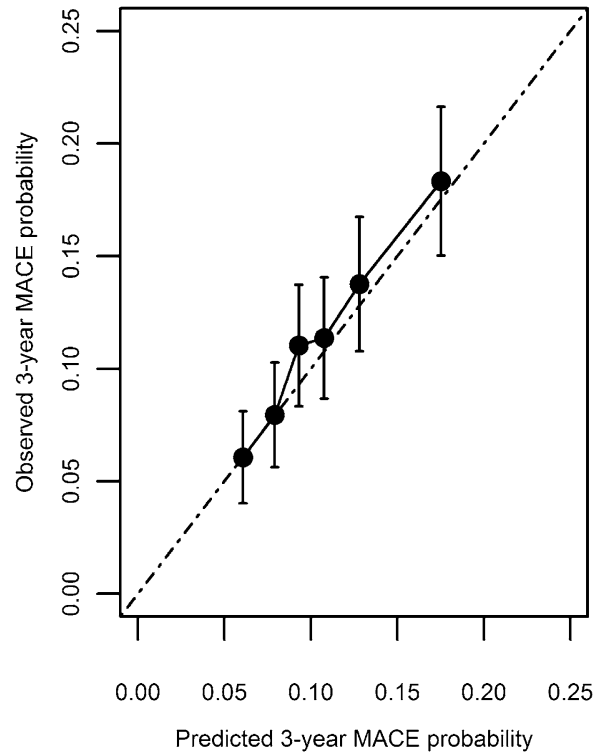

SMART - patients with vascular disease

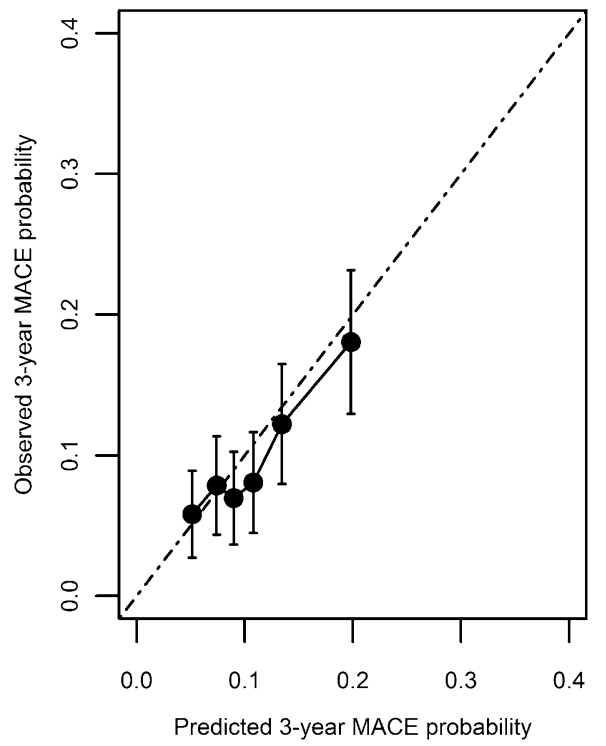

ASCOT-LLA - patients without vascular disease

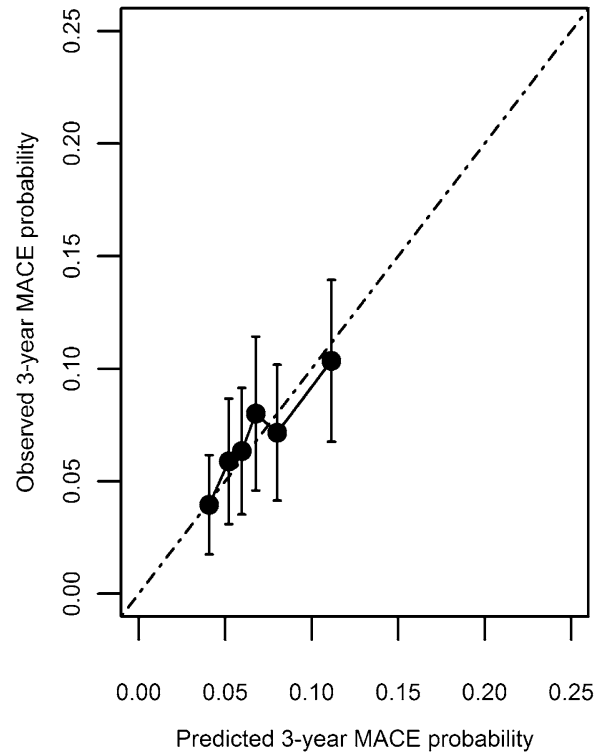

Fig. 1 Calibration plots of predicted versus observed MACE risk in elderly patients

illnesses. Our prediction model shows that the absolute effect of a statin on MACE is influenced by individual patient characteristics. With the use of this prediction model those individuals who benefit most from statin treatment can be identified. A patient's advantage of statin therapy in terms of reduction of absolute MACE risk can be estimated and weighed against potential harms of treatment and the costs of statin therapy, even though these are low, in making a treatment decision. A potential harm of statin therapy found in the PROSPER trial was an increase in cancer incidence [4]. However, a meta-analysis of 35 large randomised controlled trials found an equal risk of cancer in those with and without statins [31]. Even so, there was no increased cancer risk in statin users during the extensive 8-11 year follow-up of both the PROSPER and ASCOT-LLA trial [32, 33]. In patients aged $>70$ years from the ASCOT-LLA population $(n=2415)$, atorvastatin did not raise cancer risk (sHR $0.83,95 \%$ CI 0.58-1.20). Therefore, it is likely that statin therapy does not increase cancer incidence. For adequate estimations of MACE risk and the absolute risk reduction with a statin, death due to cancer was taken into account as a competing event.

Apart from the estimation of individual absolute statin treatment effects, these models inform physicians and 

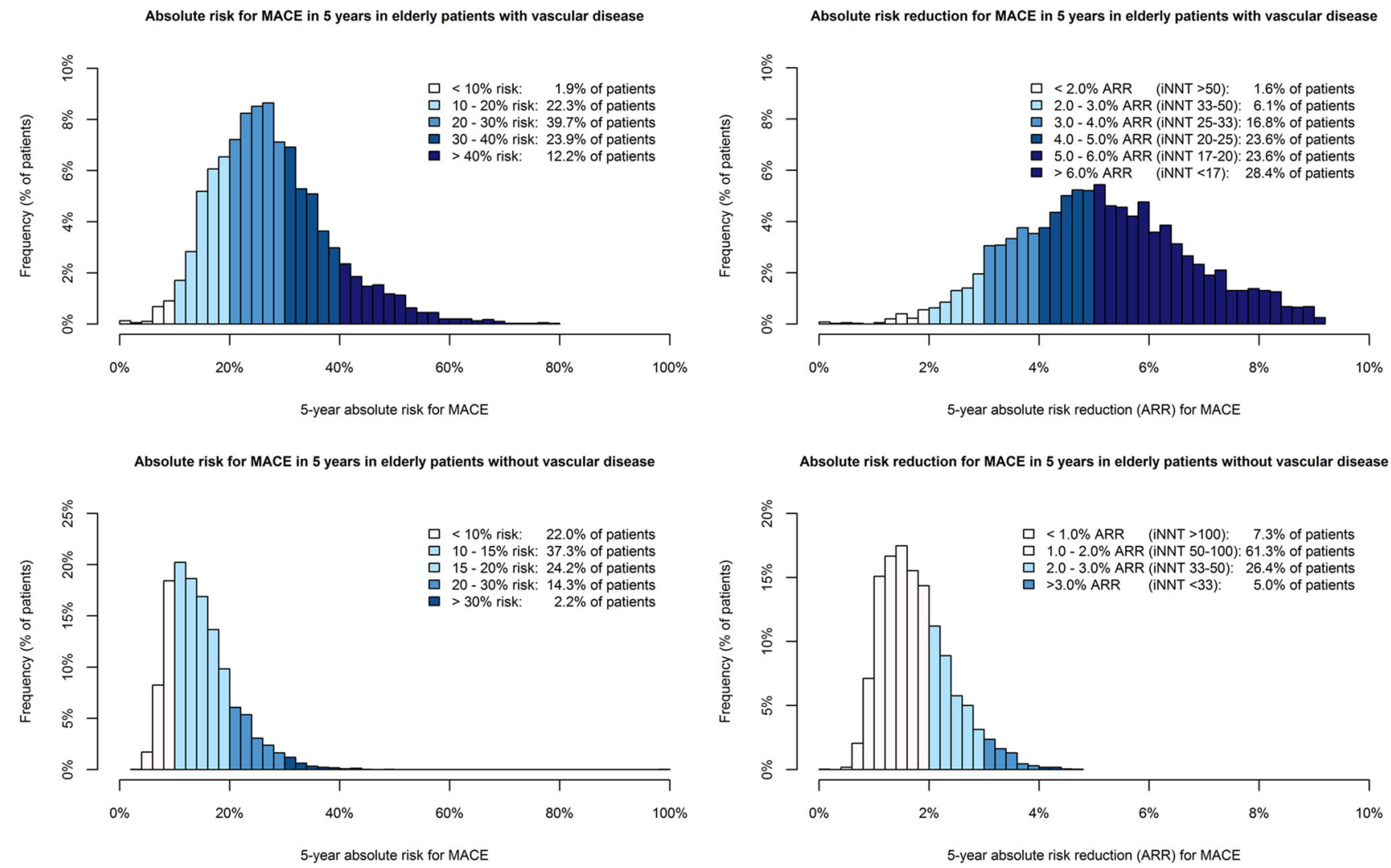

Fig. 2 Distribution of 5-year absolute risk for MACE and the absolute risk reduction with statin therapy in elderly patients
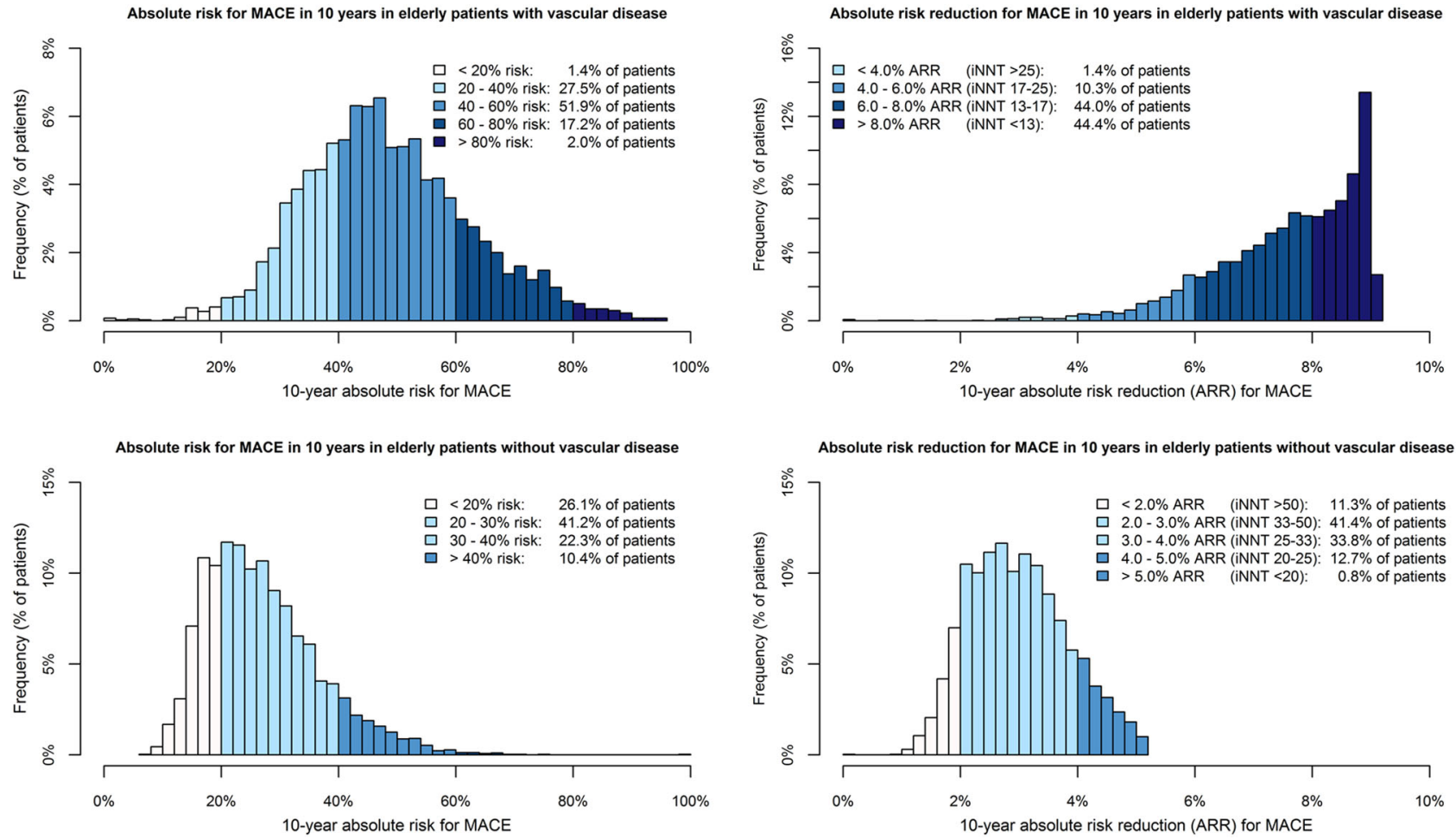

Fig. 3 Distribution of 10-year absolute risk for MACE and the absolute risk reduction with statin therapy in elderly patients 
patients about an individual's 5-year or 10-year risk for MACE. Thereby the need for preventive medical and lifestyle interventions could be established. Informing patients about their risk and engaging them in treatment decisionmaking might stimulate treatment adherence [34]. Vascular risk estimation in elderly patients has been challenging and the Systematic Coronary Risk Evaluation (SCORE), QRISK2 and Framingham/Pooled Cohort Equations risk charts are not validated for patients $>65$ years, $>74$ years and $>79$ years of age, respectively $[10,35,36]$. Furthermore, they do not take into account that many elderly patients die from a nonvascular cause. One risk score for patients aged $\geq 65$ years accounted for competing events like the risk score in this study, but that study included only patients without vascular disease and the outcome was coronary artery events instead of MACE as in this study [17]. Interestingly, LDL-cholesterol was a weak predictor for MACE in both patients with and without vascular disease. Other risk factors contribute more to risk prediction in the elderly. As our aim was to predict individual absolute benefit from statin therapy we did not assess causality. Previous studies showed no or an inverse association between LDL-cholesterol and all-cause mortality [37]. In the PROSPER trial pravastatin lowered MACE risk with $15 \%$ whereas it had no effect on all-cause mortality, which implies that the causal association between LDLcholesterol and MACE may differ from the association between LDL-cholesterol and mortality.

\section{Strengths and limitations}

A strength of this study is that the prediction models were derived and externally validated in an elderly population. Moreover, the variable 'number of medications' was added to the models as a proxy for comorbidity [38, 39]. Also, we accounted for competing events (death due to a nonvascular cause) in our statistical analysis. Furthermore, the model for those with vascular disease was validated in a patient population from a cohort study. Thereby, we show that our model is generalizable to a broad elderly population and not restricted to relatively healthy patients in trials. There are some limitations of this study. Overall discriminative ability of these models was moderate, and low in the ASCOT-LLA population. This could be explained by the homogeneity of trial populations in general and of the ASCOT-LLA population in particular with a small range in MACE risk [40]. The adequate calibration of these models may be more important in assessing model validity, as we aim to accurately predict MACE risk and the absolute statin treatment effect for the individual elderly patient. In the PROSPER and ASCOT-LLA trial, fixed statin doses were given and dosing was not titrated to a specific LDLcholesterol target. Patients in the SMART study used different statins and dosages. It could be that treatment effects for more potent statins or dosages are underestimated with the current model [41]. In sensitivity analyses we established what the individual absolute risk reduction might be with atorvastatin $20 \mathrm{mg}$ or the treatment effect from a meta-analysis in elderly subgroups from statin trials. These results should be interpreted with caution as the meta-analysis was performed in slightly older patients ( $\geq 75$ years) for an LDL-reduction of $1 \mathrm{mmol} / \mathrm{l}$, for a different vascular outcome and not taking competing risks into account [25]. Finally, our results cannot be extrapolated to the very old ( $\geq 85$ years) and to patients with chronic kidney disease stage IV or V (eGFR $<30 \mathrm{ml} / \mathrm{min}$ ), since they were not enrolled in these studies.

\section{Conclusions}

A multivariable prediction model can be used to quantify the absolute MACE risk and absolute MACE risk reduction in 5 and 10 years by statin therapy in individual elderly patients with and without vascular disease. Most elderly patients with vascular disease have high predicted absolute MACE risk reduction by a statin and it is most beneficial to treat them all with a statin for secondary prevention of vascular disease. The prediction model identifies the elderly patients who benefit most (i.e., meaningfully in terms of ARR) from statin therapy for primary prevention of MACE. The model could help physicians in managing vascular risk in their elderly patients, a population rapidly rising in prevalence.

Acknowledgments We gratefully acknowledge the contribution of the SMART research nurses; R. van Petersen (data-manager); B. G. F. Dinther (vascular manager) and the participants of the SMART Study Group: A. Algra MD, PhD; Y. van der Graaf, MD, PhD; D. E. Grobbee, MD, PhD; G. E. H. M. Rutten, MD, PhD, Julius Center for Health Sciences and Primary care; F. L. J. Visseren, MD, PhD, Department of Internal Medicine; G. J. de Borst, MD, PhD, Department of Vascular Surgery; L. J. Kappelle, MD, PhD, Department of Neurology; T. Leiner, MD, PhD, Department of Radiology; P. A. Doevendans, MD, PhD, Department of Cardiology. No compensation was received for these contributions. This work was financially supported by ZonMw, the Netherlands Organization for Health Research and Development (Grant No. 836011027).

\section{Compliance with ethical standards}

Conflict of interest JWJ/his department has received research grants from and/or was speaker (with or without lecture fees) on a.o. (CME accredited) meetings sponsored by Amgen, Astellas, Anthera, AstraZeneca, Bayer, Biotronik, Boston Scientific, Daiichi Sankyo, Lilly, Genzyme, Medtronic, Merck-Schering-Plough, Pfizer, Orbus Neich, Novartis, Roche, Servier, Sanofi Aventis, The Medicine Company, the Netherlands Heart Foundation, CardioVascular Research the Netherlands (CVON), the Interuniversity Cardiology Institute of the Netherlands and the European Community Framework KP7 Programme. AG received a travel grant from Pfizer inc. NS reports 
personal fees from Amgen, personal fees from Astrazeneca, personal fees from Merck, during the conduct of the study. MCS-S, FLJV, YvdG, NRP, PWM, PKM and ST have nothing to disclose.

Ethical standards All studies have been approved by the appropriate ethics committee and have therefore been performed in accordance with the ethical standards laid down in the 1964 Declaration of Helsinki and its later amendments. All persons gave their informed consent prior to their inclusion in the study.

Open Access This article is distributed under the terms of the Creative Commons Attribution 4.0 International License (http://crea tivecommons.org/licenses/by/4.0/), which permits unrestricted use, distribution, and reproduction in any medium, provided you give appropriate credit to the original author(s) and the source, provide a link to the Creative Commons license, and indicate if changes were made.

\section{References}

1. Prince MJ, Wu F, Guo Y, Gutierrez Robledo LM, O’Donnell M, Sullivan R, Yusuf S (2015) The burden of disease in older people and implications for health policy and practice. Lancet 385:549-562

2. Jaguszewski M, Ghadri JR, Diekmann J, Bataiosu RD, Hellermann JP, Sarcon A, Siddique A, Baumann L, Stahli BE, Luscher TF, Maier W, Templin C (2015) Acute coronary syndromes in octogenarians referred for invasive evaluation: treatment profile and outcomes. Clin Res Cardiol 104:51-58

3. Hollander M, Koudstaal PJ, Bots ML, Grobbee DE, Hofman A, Breteler MM (2003) Incidence, risk, and case fatality of first ever stroke in the elderly population. The Rotterdam study. J Neurol Neurosurg Psychiatry 74:317-321

4. Shepherd J, Blauw GJ, Murphy MB, Bollen EL, Buckley BM, Cobbe SM, Ford I, Gaw A, Hyland M, Jukema JW, Kamper AM, Macfarlane PW, Meinders AE, Norrie J, Packard CJ, Perry IJ, Stott DJ, Sweeney BJ, Twomey C, Westendorp RG (2002) Pravastatin in elderly individuals at risk of vascular disease (PROSPER): a randomised controlled trial. Lancet 360:1623-1630

5. Kutner JS, Blatchford PJ, Taylor DH Jr, Ritchie CS, Bull JH, Fairclough DL, Hanson LC, LeBlanc TW, Samsa GP, Wolf S, Aziz NM, Currow DC, Ferrell B, Wagner-Johnston N, Zafar SY, Cleary JF, Dev S, Goode PS, Kamal AH, Kassner C, Kvale EA, McCallum JG, Ogunseitan AB, Pantilat SZ, Portenoy RK, PrincePaul M, Sloan JA, Swetz KM, Von Gunten CF, Abernethy AP (2015) Safety and benefit of discontinuing statin therapy in the setting of advanced, life-limiting illness: a randomized clinical trial. JAMA Intern Med 175:691-700

6. Stone NJ, Robinson JG, Lichtenstein AH, Bairey Merz CN, Blum CB, Eckel RH, Goldberg AC, Gordon D, Levy D, Lloyd-Jones DM, McBride P, Schwartz JS, Shero ST, Smith SC Jr, Watson K, Wilson PW, Eddleman KM, Jarrett NM, LaBresh K, Nevo L, Wnek J, Anderson JL, Halperin JL, Albert NM, Bozkurt B, Brindis RG, Curtis LH, DeMets D, Hochman JS, Kovacs RJ, Ohman EM, Pressler SJ, Sellke FW, Shen WK, Tomaselli GF (2014) 2013 ACC/AHA guideline on the treatment of blood cholesterol to reduce atherosclerotic cardiovascular risk in adults: a report of the American College of Cardiology/American Heart Association Task Force on Practice Guidelines. Circulation 129:S1-S45

7. Reiner Z, Catapano AL, De Backer G, Graham I, Taskinen MR, Wiklund O, Agewall S, Alegria E, Chapman MJ, Durrington P,
Erdine S, Halcox J, Hobbs R, Kjekshus J, Filardi PP, Riccardi G, Storey RF, Wood D (2011) ESC/EAS Guidelines for the management of dyslipidaemias: the Task Force for the management of dyslipidaemias of the European Society of Cardiology (ESC) and the European Atherosclerosis Society (EAS). Eur Heart J 32:1769-1818

8. Fleg JL, Forman DE, Berra K, Bittner V, Blumenthal JA, Chen MA, Cheng S, Kitzman DW, Maurer MS, Rich MW, Shen WK, Williams MA, Zieman SJ (2013) Secondary prevention of atherosclerotic cardiovascular disease in older adults: a scientific statement from the American Heart Association. Circulation 128:2422-2446

9. National Clinical Guideline Centre (UK) (2014) Lipid Modification: Cardiovascular Risk Assessment and the Modification of Blood Lipids for the Primary and Secondary Prevention of Cardiovascular Disease. NICE, London

10. Hippisley-Cox J, Coupland C, Vinogradova Y, Robson J, Minhas $\mathrm{R}$, Sheikh A, Brindle P (2008) Predicting cardiovascular risk in England and Wales: prospective derivation and validation of QRISK2. BMJ 336:1475-1482

11. Cournot M, Cambou JP, Quentzel S, Danchin N (2006) Key factors associated with the under-prescription of statins in elderly coronary heart disease patients: results from the ELIAGE and ELICOEUR surveys. Int J Cardiol 111:12-18

12. Dorresteijn JA, Visseren FL, Ridker PM, Wassink AM, Paynter NP, Steyerberg EW, van der Graaf Y, Cook NR (2011) Estimating treatment effects for individual patients based on the results of randomised clinical trials. BMJ 343:d5888

13. van der Leeuw J, Ridker PM, van der Graaf Y, Visseren FL (2014) Personalized cardiovascular disease prevention by applying individualized prediction of treatment effects. Eur Heart J 35:837-843

14. Sever PS, Dahlof B, Poulter NR, Wedel H, Beevers G, Caulfield M, Collins R, Kjeldsen SE, Kristinsson A, McInnes GT, Mehlsen J, Nieminen M, O'Brien E, Ostergren J (2003) Prevention of coronary and stroke events with atorvastatin in hypertensive patients who have average or lower-than-average cholesterol concentrations, in the Anglo-Scandinavian Cardiac Outcomes Trial-Lipid Lowering Arm (ASCOT-LLA): a multicentre randomised controlled trial. Lancet 361:1149-1158

15. Simons PC, Algra A, van de Laak MF, Grobbee DE, van der Graaf $Y$ (1999) Second manifestations of ARTerial disease (SMART) study: rationale and design. Eur J Epidemiol 15:773-781

16. Wolbers M, Koller MT, Witteman JC, Steyerberg EW (2009) Prognostic models with competing risks: methods and application to coronary risk prediction. Epidemiology 20:555-561

17. Koller MT, Leening MJ, Wolbers M, Steyerberg EW, Hunink MG, Schoop R, Hofman A, Bucher HC, Psaty BM, Lloyd-Jones DM, Witteman JC (2012) Development and validation of a coronary risk prediction model for older US and European persons in the Cardiovascular Health Study and the Rotterdam Study. Ann Intern Med 157:389-397

18. Nelson MR, Ramsay E, Ryan P, Willson K, Tonkin AM, Wing L, Simons L, Reid CM (2012) A score for the prediction of cardiovascular events in the hypertensive aged. Am J Hypertens 25:190-194

19. Roe MT, Chen AY, Thomas L, Wang TY, Alexander KP, Hammill BG, Gibler WB, Ohman EM, Peterson ED (2011) Predicting long-term mortality in older patients after non-STsegment elevation myocardial infarction: the CRUSADE longterm mortality model and risk score. Am Heart J 162(875-83):e1

20. Levey AS, Bosch JP, Lewis JB, Greene T, Rogers N, Roth D (1999) A more accurate method to estimate glomerular filtration rate from serum creatinine: a new prediction equation. Modification of Diet in Renal Disease Study Group. Ann Intern Med 130:461-470 
21. Donders AR, van der Heijden GJ, Stijnen T, Moons KG (2006) Review: a gentle introduction to imputation of missing values. J Clin Epidemiol 59:1087-1091

22. Steyerberg EW (2009) Clinical prediction models: a practical approach to development, validation and updating. Springer, New York

23. Harrell FE (2001) Regression modelling strategies: with applications to linear models, logistic regression and survival analysis. Springer, New York

24. Law MR, Wald NJ, Rudnicka AR (2003) Quantifying effect of statins on low density lipoprotein cholesterol, ischaemic heart disease, and stroke: systematic review and meta-analysis. BMJ 326:1423

25. Baigent C, Blackwell L, Emberson J, Holland LE, Reith C, Bhala N, Peto R, Barnes EH, Keech A, Simes J, Collins R (2010) Efficacy and safety of more intensive lowering of LDL cholesterol: a meta-analysis of data from 170,000 participants in 26 randomised trials. Lancet 376:1670-1681

26. Vickers AJ, Kattan MW, Daniel S (2007) Method for evaluating prediction models that apply the results of randomized trials to individual patients. Trials 8:14

27. Sergi G, De Rui M, Sarti S, Manzato E (2011) Polypharmacy in the elderly: can comprehensive geriatric assessment reduce inappropriate medication use? Drugs Aging 28:509-518

28. Ewen S, Baumgarten T, Rettig-Ewen V, Mahfoud F, GrieseMammen N, Schulz M, Bohm M, Laufs U (2015) Analyses of drugs stored at home by elderly patients with chronic heart failure. Clin Res Cardiol 104:320-327

29. Ming EE, Davidson MH, Gandhi SK, Marotti M, Miles CG, Ke X, McKenney JM (2008) Concomitant use of statins and CYP3A4 inhibitors in administrative claims and electronic medical records databases. J Clin Lipidol 2:453-463

30. Pedro-Botet J, Climent E, Chillaron JJ, Toro R, Benaiges D, Flores-Le Roux JA (2015) Statins for primary cardiovascular prevention in the elderly. J Geriatr Cardiol 12:431-438

31. Bonovas S, Filioussi K, Tsavaris N, Sitaras NM (2006) Statins and cancer risk: a literature-based meta-analysis and meta-regression analysis of 35 randomized controlled trials. J Clin Oncol 24:4808-4817

32. Sever PS, Chang CL, Gupta AK, Whitehouse A, Poulter NR, Investigators A (2011) The Anglo-Scandinavian Cardiac Outcomes Trial: 11-year mortality follow-up of the lipid-lowering arm in the U.K. Eur Heart J 32:2525-2532

33. Lloyd SM, Stott DJ, de Craen AJ, Kearney PM, Sattar N, Perry I, Packard CJ, Briggs A, Marchbank L, Comber H, Jukema JW,
Westendorp RG, Trompet S, Buckley BM, Ford I (2013) Longterm effects of statin treatment in elderly people: extended follow-up of the PROspective study of Pravastatin in the elderly at risk (PROSPER). PLoS One 8:e72642

34. Osterberg L, Blaschke T (2005) Adherence to medication. N Eng J Med 353:487-497

35. Goff DC Jr, Lloyd-Jones DM, Bennett G, Coady S, D'Agostino RB, Gibbons R, Greenland P, Lackland DT, Levy D, O'Donnell CJ, Robinson JG, Schwartz JS, Shero ST, Smith SC Jr, Sorlie P, Stone NJ, Wilson PW, Jordan HS, Nevo L, Wnek J, Anderson JL, Halperin JL, Albert NM, Bozkurt B, Brindis RG, Curtis LH, DeMets D, Hochman JS, Kovacs RJ, Ohman EM, Pressler SJ, Sellke FW, Shen WK, Tomaselli GF (2014) 2013 ACC/AHA guideline on the assessment of cardiovascular risk: a report of the American College of Cardiology/American Heart Association Task Force on Practice Guidelines. Circulation 129:S49-S73

36. Conroy RM, Pyorala K, Fitzgerald AP, Sans S, Menotti A, De Backer G, De Bacquer D, Ducimetiere P, Jousilahti P, Keil U, Njolstad I, Oganov RG, Thomsen T, Tunstall-Pedoe H, Tverdal A, Wedel H, Whincup P, Wilhelmsen L, Graham IM (2003) Estimation of ten-year risk of fatal cardiovascular disease in Europe: the SCORE project. Eur Heart J 24:987-1003

37. Ravnskov U, Diamond DM, Hama R, Hamazaki T, Hammarskjold B, Hynes N, Kendrick M, Langsjoen PH, Malhotra A, Mascitelli L, McCully KS, Ogushi Y, Okuyama H, Rosch PJ, Schersten T, Sultan S, Sundberg R (2016) Lack of an association or an inverse association between low-density-lipoprotein cholesterol and mortality in the elderly: a systematic review. BMJ Open 6:e010401

38. Proietti M, Raparelli V, Olshansky B, Lip GY (2016) Polypharmacy and major adverse events in atrial fibrillation: observations from the AFFIRM trial. Clin Res Cardiol 105:412-420

39. Franchi C, Marcucci M, Mannucci PM, Tettamanti M, Pasina L, Fortino I, Bortolotti A, Merlino L, Nobili A (2016) Changes in clinical outcomes for community-dwelling older people exposed to incident chronic polypharmacy: a comparison between 2001 and 2009. Pharmacoepidemiol Drug Saf 25:204-211

40. Cook NR (2007) Use and misuse of the receiver operating characteristic curve in risk prediction. Circulation 115:928-935

41. Wenger NK, Lewis SJ, Herrington DM, Bittner V, Welty FK (2007) Outcomes of using high- or low-dose atorvastatin in patients 65 years of age or older with stable coronary heart disease. Ann Intern Med 147:1-9 